\title{
(VI)VIDA NO QUE SE TEM DE MAIS PROFUNDO: A DEPRESSÃO NA ADOLESCÊNCIA E UM OLHAR DE ENFRENTAMENTO À LUZ DA ABORDAGEM CENTRADA NA PESSOA
}

\author{
(SAW)LIFE AT ITS DEEPEST: DEPRESSION IN ADOLESCENCE AND A VIEW OF \\ COPING IN THE LIGHT OF THE PERSON-CENTERED APPROACH
}

\author{
Marlon Diettrich ${ }^{1}$ \\ Luzia de Miranda Meurer²
}

\begin{abstract}
RESUMO: A adolescência é uma fase do desenvolvimento humano, a qual envolve diversas transformações e situações vivenciadas pelo adolescente que por vezes podem cooperar para o desencadeamento da depressão. Esta pesquisa teve como objetivo elucidar como a depressão na adolescência pode ser possivelmente compreendida e manejada pela Abordagem Centrada na Pessoa (ACP). Inicialmente procura-se identificar possíveis fatores que possam contribuir para o surgimento da depressão na adolescência e, posteriormente, expõe-se a perspectiva de atuação diante a esta abordagem psicológica. Quanto à natureza da pesquisa se considerou básica, de abordagem qualitativa e utilizou-se como método a pesquisa bibliográfica. A reprodução da análise tratou-se de uma revisão narrativa, tendo como forma de interpretar os dados apresentados à Análise Temática. Os resultados obtidos identificaram a diversidade de fatores que são capazes de contribuir para o desenvolvimento da depressão na adolescência. Desde as transformações físicas e neuroquímicas que se apresentam, o histórico familiar genético, questões emocionais e comportamentais vivenciadas, estereótipos empregados sobre os adolescentes, possíveis influências dos adultos, as dinâmicas familiares e interações sociais, foram fatores identificados que possivelmente vulnerabilizam a instalação da doença. Constatou-se contribuições perante a ACP e sua forma de atuação defronte a esse fenômeno. Essa abordagem procura focalizar a pessoa em sua totalidade, tendo confiança na tendência atualizante, que é a capacidade do ser humano para compreender a si mesmo, modificarse e se atualizar. Podendo favorecê-la quando o terapeuta fornece um ambiente facilitador, com atitudes facilitadoras fundamentais, para que a pessoa consiga se expressar, se perceber e encontrar as suas próprias potencialidades.
\end{abstract}

Palavras-chave: Depressão. Adolescência. Abordagem centrada na pessoa. Tendência atualizante. Atitudes facilitadoras.

ABSTRACT: Adolescence is a phase of human development that involves several transformations and situations experienced by adolescents, that can sometimes cooperate in triggering depression. This research aimed to elucidate how depression in adolescence can be understood and managed by the Person-Centered Approach (PCA). Initially, it seeks to identify possible factors that may contribute to the onset of depression in adolescence and, later, the perspective of acting on this psychological approach is exposed. The nature of the research is considered basic, with a qualitative approach, using bibliographic research as a method. The reproduction of the analysis was a narrative review, using the Thematic Analysis to interpret the data presented. The results obtained identified the diversity of factors that can contribute to the development of depression in adolescence. The physical and neurochemical changes that occur, genetic family history, emotional and behavioral

${ }^{1}$ Acadêmico da ro ${ }^{\text {a }}$ fase do curso de Psicologia da UNIFEBE. E-mail: marlon.diettrich@unifebe.edu.br ${ }^{2}$ Professora do Curso de Psicologia da UNIFEBE e orientadora deste estudo. Mestra em Educação pela Universidade Regional de Blumenau - FURB. Graduada em Psicologia pela Universidade Federal de Santa Catarina-UFSCeE-mail: luzia.meurer@unifebe.edu.br. 
issues experienced, stereotypes used on adolescents, possible influences from adults, family dynamics and social interactions, were identified factors that possibly make the onset of the disease more vulnerable. It was verified the contributions to the PCA and its way of acting against this phenomenon. This approach seeks to focus on the person, having confidence in the actualizing trend, which is the human being's ability to understand himself, change and update himself. It can be favored when the therapist provides a facilitating environment, with fundamental facilitating attitudes, so that the person can express themselves, perceive themselves and find their potential.

Keywords: Depression. Adolescence. Person-centered approach. Updating trend. Facilitating attitudes.

\section{INTRODUÇÃO}

O número de pessoas que vivem com depressão está aumentando drasticamente em todo o mundo. Cerca de I8\% entre 2005 e 2015. Em 2017, a doença já afetava 4,4\% da população mundial. O Brasil é o segundo país com maior número de depressivos nas Américas, com 5,8\% da população diagnosticada, ficando atrás somente dos Estados Unidos, com 5,9\% de pessoas acometidas pela depressão, segundo a Organização Mundial da Saúde - OMS (2017). Dados do Instituto Brasileiro de Geografia e Estatística - IBGE (2019), também confirmam um aumento expressivo, quando expõem que o percentual de brasileiros que declara ter recebido o diagnóstico de depressão, mediante a um profissional de saúde mental; subiu $34,2 \%$ em seis anos. Estima-se que o Brasil possui 16,3 milhões de pessoas identificadas com depressão. Mostra a Pesquisa Nacional de Saúde (PNS) em 2019, num levantamento realizado com 108 mil domicílios, que ı, 2\% das pessoas de 18 anos ou mais de idade receberam diagnóstico de depressão, contra 7,6\% em 2013. Em mulheres, a prevalência da doença é maior, cerca de $14,7 \%$, diante de 5,1\% nos homens. Entre as pessoas que informaram sobre o diagnóstico de depressão, I8,9\% faziam psicoterapia e 48\% usaram medicamentos para a doença nas duas últimas semanas anteriores à pesquisa.

Nessa perspectiva, vale lembrar que não é só na faixa etária acima dos I8 anos que o número de pessoas com depressão vem crescendo, levando em conta o período da adolescência, dados do Ministério da Saúde (2019) entram em cena, mostrando um aumento de $15 \%$ totais no número de atendimentos de jovens de 15 a 29 anos, no Sistema Único de Saúde (SUS) relacionados à depressão, entre 2015 e 2018. Um estudo realizado pela Universidade Johns Hopkins, em 2016, demonstrou que a depressão entre adolescentes cresceu $37 \%$ entre os anos de 2005 e 2014. Segundo as análises produzidas pelos pesquisadores, 
os dados se estabilizaram até 20II, mas tiveram um aumento significativo entre 2011 e 2014 . Outrossim, Monteiro (2012) sinaliza que se deve considerar importante o estudo da depressão em crianças e adolescentes, pois isso ajuda a evitar o estabelecimento de complicações agravantes decorrentes de sua manifestação. Os adolescentes podem se apresentar tão vulneráveis à depressão quanto os adultos. Eles passam por pressão social e encarram novas situações em suas vidas, que podem cooperar para o desencadeamento da depressão. Dessa forma, são capazes de demonstrar rebeldia, confusão, angústia e outros sinais depressivos, e ainda mais, não dada atenção a tal problemática, alguns casos podem se agravar expressivamente e, em consequência, favorecer a prática do suicídio.

Importante ressaltar que os dados anteriormente apresentados, foram publicados antes do surgimento da pandemia COVID-19. Em concordância com Ministério da Saúde do Brasil (2020), levando em conta o cenário atual, um evento como esse pode ocasionar perturbações psicológicas e sociais que afetam a capacidade de enfrentamento de toda a sociedade, em variados níveis de intensidade e propagação. Com o surgimento da pandemia, o número de casos no que diz respeito ao sofrimento psíquico aumentaram demasiadamente, havendo como estima, que entre um terço e metade da população exposta a uma epidemia possa sofrer alguma manifestação psicopatológica, caso não seja feita nenhuma intervenção de cuidado específico para as reações e sintomas esperados (FIOCRUZ, 2020). De acordo com a OMS (2020), durante a crise da COVID-19, houve aumento de sintomas, tais como: ansiedade, depressão, estresse, esforço excessivo para verificar sintomas, tanto em si quanto em outras pessoas, irritabilidade, sentimento de insegurança e inquietude, receio de que dores naturais pudessem ser causadas pelo vírus, dificuldade para dormir, sentimento de desamparado, de falta de controle e pensamentos incoerentes. Ademais, pode-se interpretar assim, em resposta a tal cenário enfrentado, que ele trouxe à tona também as suas contribuições para maiores chances de manifestação da depressão.

Em suma, o interesse que motivou o estudo desta temática, apresentou-se primordialmente, por causa do aumento no número de pessoas depressivas manifestados na adolescência, de acordo com a literatura científica exposta. Adicionado a isso, pelo fato de o primeiro autor deste artigo ter vivenciado o fenômeno da depressão em sua adolescência. Tendo atravessado uma parte de seu adolescer, desse ciclo vital de sua vida, marcado 
profundamente pela manifestação da doença. Diante dos fatores que vulnerabilizaram o ocorrido em sua vida, pelo sofrimento apresentado ante a doença, perante o diagnóstico que se consolidou e diante do tratamento que obtivera, nortearam, assim, o desejo e apreço em escrever sobre o tema no presente momento, procurando levar em conta essa conjuntura, a adolescência e a manifestação da depressão nessa etapa da vida.

Por tudo isso, esta pesquisa teve como objetivo elucidar como a depressão na adolescência pode ser possivelmente compreendida e manejada pela Abordagem Centrada na Pessoa (ACP). Esta que contribuiu consideravelmente para o desenvolvimento da psicologia como ciência e profissão, o modo como ela expressa sua linha de pensamento e integra a sua prática em busca da saúde integral do ser, fez brilhar os olhos do autor. Por tais razões, buscou-se descrevê-la nesta pesquisa, contemplando um olhar de enfrentamento à depressão na adolescência.

No que diz respeito à metodologia praticada, a natureza da pesquisa pode ser considerada como básica. Tendo como abordagem a qualitativa, quanto ao tipo, tratou-se de uma pesquisa exploratória. O método adotado tratou-se de uma revisão narrativa, utilizando como maneira de interpretar os dados colhidos, a análise temática.

O trabalho inicialmente procura explanar a depressão e seus impactos na contemporaneidade, fala sobre a adolescência, perpassa falando conjuntamente sobre depressão e a sua manifestação na adolescência, descreve em sequência, a psicologia e o cuidado com o ser humano. Posteriormente, demonstra alguns fatores que podem contribuir para o surgimento da depressão na adolescência e, por último, escreve sobre a Abordagem Centrada na Pessoa de Carl Rogers e algumas de suas possíveis contribuições, em face da manifestação da depressão no período da adolescência, com a finalidade de expor uma perspectiva de atuação perante a sua práxis.

\section{REFERENCIAL TEÓRICO}

A depressão, a despeito de ser uma temática explicitamente discutida e estudada, é um fenômeno de caráter ascendente diante da sociedade pós-moderna, principalmente na sua ocorrência entre os adolescentes. Vem sendo objeto de estudo em pesquisas de várias áreas do conhecimento. A filosofia, sociologia, psicologia, medicina e demais ciências, 
procuram contribuir com seus saberes defronte o surgimento de tal fenômeno (MELO; SIEBRA; MOREIRA, 2017).

\section{I DEPRESSÃO E SEUS IMPACTOS NO CENÁRIO PÓS-MODERNO}

De acordo com a Organização Pan-Americana de Saúde OPAS (2021), a depressão é um transtorno comum em todo o mundo; estima-se que existam mais de 300 milhões de pessoas sofrendo com ela. Sua manifestação, é diferente das habituais oscilações de humor e das respostas emocionais breves que permeiam as vivências do dia a dia. Sobretudo, quando de longa duração e com intensidade moderada ou grave, a depressão pode se tornar uma crítica condição de saúde. Ela pode causar à pessoa afetada um grande sofrimento global na vida desta, por exemplo, disfunções no trabalho, na escola ou no meio familiar. Na pior das circunstâncias, ressalta-se que a depressão pode levar ao caminho do suicídio.

Sobre suas causas, a depressão apresenta-se como uma doença multifatorial, estando envolvida no seu surgimento, a relação entre o ambiente, predisposição genética, alterações genéticas e eventos ao longo do desenvolvimento, que vão levar a alterações estruturais e neuroquímicas do sistema nervoso central da pessoa, resultando em características que se apresentam de maneira mais ou menos estáveis no ser (SAMPAIO; FIGUEIRA; AFONSO, 2014).

Como resultado, ocorrem as respostas que, dadas pelo organismo e manifestadas pela pessoa, nesse sentido, apresentam-se os principais sintomas de depressão: tristeza, desânimo, angústia, falta de vontade, choro com facilidade e anedonia, esta última muito característica. Outros sintomas importantes aparentes: são alterações no apetite, no peso e no sono, diminuição da libido, agitação ou retardo psicomotor. O padrão de pensamentos da pessoa deprimida também se abala, estando relacionado com sentimentos de inferioridade, desvalorização, incompetência, culpa, dificuldade para tomar decisões e concentrar-se. Esses pensamentos podem se relacionar ou não com ideias, desejo ou tentativa de morte (ANDRETTA; OLIVEIRA, 20II). Sampaio, Figueira e Afonso (2014) mencionam que diferenciar esses tipos de mudanças de humor, ou seja, as consideradas normais das que vão se alterando para graus mais graves, pode não ser fácil, dado que na depressão os sintomas ocorrem num contínuo de gravidade, entre o normal, aquela tristeza que todos sentimos em 
nossas vidas, do que se torna patológico. Nesse sentido, Baptista (2012) cita que os critérios para diagnóstico da depressão são baseados nos manuais de diagnóstico internacionais. Apesar de a existência de diferentes classificações, ambos estabelecem critérios baseados na quantidade e qualidade dos sintomas. Nisso, um dos principais manuais internacionais utilizados no diagnóstico de perturbações mentais, é o Manual de Diagnóstico e Estatístico dos Transtornos Mentais - DSM-V (AMERICAN PSYCHIATRIC ASSOCIATION, APA, 2014).

De acordo com a APA (2014), no DSM-V o diagnóstico de depressão se estabelece quando presente pelo menos cinco de um total de nove sintomas apresentados, que envolvem a prevalência do humor triste, mas também sintomas como: diminuição do interesse ou prazer em atividades diárias, perda ou ganho de peso sem estar fazendo dieta, insônia ou sonolência quase todos os dias, cansaço ou perda de energia, sentimentos de inutilidade e culpa excessiva, baixa autoestima, capacidade diminuída para pensar ou se concentrar, indecisão, entre outros. Eles devem persistir durante o mesmo período de duas semanas, existindo pelo menos um ou dois dos principais sintomas, ou seja, o humor deprimido e a perda de interesse ou prazer. Os demais sintomas que complementam o quadro são referentes a ganho ou perda de peso, insônia ou hipersonia, agitação ou retardo psicomotor, fadiga e perda de energia, sentimentos de inutilidade, culpa, baixa concentração e ideação suicida.

Convém refletir que, apesar de várias críticas aos critérios diagnósticos sugeridos pelo manual, é importante citar que eles são critérios universalizados sobre psicopatologias, que possibilitam padronizações no diagnóstico e intervenções, além de facilitar a comunicação entre profissionais de saúde (BORSBOOM, 2008; WIDIGER; SAMUEL, 2005). De acordo com Baptista (2018), o diagnóstico de depressão vem sendo utilizado como um importante recurso na Psiquiatria e Psicologia, o autor sublinha ainda que ele deve vir acompanhado de compreensão diante dos fatores de risco, protetivos e por demais variáveis associadas à psicopatologia, já que elas serão fundamentais no processo de busca de informações para intervenções mais eficazes. 


\subsection{ADOLESCÊNCIA}

A palavra adolescente deriva da expressão latina adolescere, que significa crescer, se desenvolver. Não se encontra consenso entre os diferentes autores ante as definições que estabelecem, contudo, a generalidade entre eles demonstra que a adolescência é uma etapa intermédia do crescimento humano, que decorre entre a infância e a idade adulta (COSLIM, 2009). Ela tem sido definida OMS como um período biológico, psicológico e social, compreendido entre os io e os I9 anos (WORLD HEALTH ORGANIZATION - WHO, 20II). No Brasil, o Estatuto da Criança e do Adolescente (ECA), Lei 8.069, de I990, considera criança a pessoa até 12 anos de idade incompletos, define a adolescência como a faixa etária de I2 a 18 anos de idade $\left(\operatorname{artigo} 2^{\circ}\right.$ ), e, em casos excepcionais e quando disposto na lei, o estatuto se torna aplicável até os 2I anos de idade (artigos I2I e I42).

A adolescência é uma construção social e um fenômeno global, foi compreendida como parte do ciclo da vida somente a partir do século XX. Antes disso, as crianças eram consideradas adultas quando obtinham a capacidade de aprender uma profissão. Hoje, observa-se a adolescência como uma transição do desenvolvimento entre a infância e a vida adulta, no qual envolve mudanças físicas, cognitivas, emocionais e sociais. Todas essas dimensões se desenvolvem simultaneamente e estão inter-relacionadas. O adolescente em meio a essas junções, depara-se com as cobranças culturais da sociedade em que vive, cobranças que assumem formas diferentes em culturas e contextos diferentes. Surgem as pressões em suas vidas, elas se conectam às expectativas que o mundo dos adultos vem exigindo, que vão muitas vezes para além da realidade vivida e tornam distante o percurso do adolescente, que quer descobrir, almejar e alcançar seus objetivos de vida, dos quais está explorando. Uma característica habitual em todas as culturas é a de que os adolescentes passam uma considerável parte do tempo em seu próprio mundo, afastando-se do mundo dos adultos (EISENSTEIN, 2005; PAPALIA; FELDMAN, 2013).

Zanella (2013) enfatiza ainda sobre esse período da vida repleto de paradoxos, no qual se estabelece uma crise adaptativa. Entre todos os ciclos da vida, o adolescer é um importante momento, no qual há um reencontro com o eu, há descobertas, escolhas, frustrações, surpresas, o despertar da sexualidade e da ousadia. De igual forma, a adolescência é de fato 
um período de muitas tentativas e erros, em que acontece o acomodamento de uma grande quantidade de informações e a busca por identidade. Segundo Ferreira e Nelas (2006), a construção da identidade é uma das tarefas essenciais que se desenvolvem na adolescência, e é nessa fase que o indivíduo adquire aos poucos uma nova subjetividade, alterando a representação de si e do outro.

\subsection{DEPRESSÃO NA ADOLESCÊNCIA}

Para Jatobá e Bastos (2007), a depressão na adolescência vem se apresentando como um fenômeno cada vez mais crescente, merecendo atenção pela sua gravidade e pelos danos que causa à saúde. Frequentemente, os profissionais da área da saúde vêm identificando sua ocorrência, o que favorece o interesse pelo estudo do fenômeno. Acerca desse período do desenvolvimento humano, como se observa anteriormente, a adolescência é uma fase a qual envolve diversos comportamentos e questionamentos enfrentados pelo jovem, que se vê perdido diante de tantas informações, pois ainda não adquiriu maturidade suficiente para lidar com os novos acontecimentos que o cerca e a construção de sua própria identidade (BIAZUS; RAMIRES, 2012).

Monteiro (2012) sinaliza que as transformações provenientes da adolescência, repercutem em suas relações e marcam o período de transição da infância para a vida adulta. É uma fase na qual o sujeito está repleto de ideias, expectativas, sonhos e projetos. O adolescente passa a buscar autonomia, e se distancia das ideações de valores consideradas pelos pais, tem-se um novo desafio: ele necessita se afirmar com suas próprias potencialidades. Por esse período se tratar de uma fase oriunda a mudanças físicas, individuais e intelectuais, muitos adolescentes se encontram perdidos, confusos e imaturos para resolverem seus conflitos, tendo como resultado uma travessia delicada para a maioridade em busca de sua subjetividade, procedendo de um descontrole emocional, dificultando o seu desenvolvimento saudável e feliz, podendo desencadear depressão (LEVISKY, 2002; BIAZUS; RAMIRES, 2012). De acordo com Crivelatti, Durman e Hofstatter (2006), a fim de identificar a depressão na adolescência, é necessário considerar os sintomas básicos: o humor depressivo, falta de reatividade, variações de humor, 
irritabilidade, excesso de culpa, anedonia, agitação motora, distúrbios alimentares, pessimismo, ideação suicida, sintomas cognitivos e o retraimento social.

\subsection{PSICOLOGIA, UMA CIÊNCIA EM DIREÇÃO AO CUIDADO DO SER HUMANO}

Schultz e Schultz (2005) salientam que no século V a.C., Platão, Aristóteles e outros sábios gregos obtinham o mesmo fascínio no qual hoje se ocupam os filósofos e psicólogos, isto é, a memória, a aprendizagem, a motivação, a percepção e, por fim, os comportamentos. Sobre essas considerações, o que difere a filosofia da psicologia moderna são as abordagens e as técnicas utilizadas, que denotaram a emergência desta última com um campo de estudo próprio, essencialmente científico.

Nesse meio histórico, a psicologia como ciência e profissão atravessou diversas etapas para se tornar uma ciência independente das outras áreas de conhecimento, tudo isso ocorrendo por meio dos esforços de pessoas que pretendiam desfrutar de seus estudos psicológicos como um território próprio para essa ciência, o desfecho e vitória se notou por

essas iniciativas e pelos espaços que foram conquistados, nas instituições de ensino universitário e de pesquisa, ocorrendo na metade do século XIX (FIGUEIREDO; SANTI, 1997). Bock, Furtado e Teixeira (1999) abrilhantam que a psicologia científica e seu status como ciência é reconhecida à medida que se liberta da Filosofia, atraindo, assim, novos estudiosos e pesquisadores, com ênfase em novos padrões de produção de conhecimento.

Ao mencionar sobre a psicologia como ciência e profissão, é preciso reconhecer sua história para compreender sua evolução e as diferentes abordagens que foram surgindo ao longo de sua trajetória, bem como sua expansão para o contexto clínico, educacional, hospitalar, industrial e outros campos de atuação (BRASIL, 1988). As Psicologias Humanistas, referem-se a uma dessas evoluções que se manifestaram, elas compuseram com psicologias fenomenológicas e existenciais a chamada terceira força da Psicologia, surgiram dando destaque ao que é propriamente humano, isto é, focando na capacidade da pessoa de significar e ressignificar a sua vida, sendo capaz de superar qualquer determinismo imposto. Essas linhas humanistas de pensamento, refutam o objetivismo e o racionalismo empregado por outras práticas. Elas buscam trabalhar com as sensações e sentidos vividos e atribuídos 
pelo ser humano, aceitando que a pessoa é capaz de dar voz a si, de dar sentido às experiências que vive, na sua relação com o mundo e as pessoas (AMATUZZI, 200I). De acordo com Hall, Lindzey e Campbell (2000), Carl Ranson Rogers (1902-1987) foi um dos idealizadores da orientação humanista da Psicologia contemporânea, que apresentou uma vertente mais otimista ao olhar para o ser humano, acreditando que qualquer pessoa tem dentro de si o potencial para se desenvolver e se ajustar na vida de forma sadia e criativa.

\subsection{A ABORDAGEM CENTRADA NA PESSOA}

Concebida pelo psicólogo norte-americano Carl Rogers, a Abordagem Centrada na Pessoa - ACP se estabeleceu como uma proposta inovadora de psicoterapia, ela tem como base o impulso individual para o crescimento e para a saúde, dando maior enfoque aos aspectos emocionais, abarcando a situação vivida no presente em vez de no passado da pessoa, a ACP busca contemplar a própria relação psicoterapêutica como uma experiência de crescimento (FONTGALLAND; MOREIRA, 20I2).

O ser humano, nessa perspectiva teórica, possui a capacidade de compreender a si e de solucionar as suas questões, de modo a garantir o seu funcionamento adequado diante de suas capacidades organísmicas, pensando em uma perspectiva integral (ROGERS, 1992). Essa capacidade, ao que Rogers (1959) a denomina de Tendência Atualizante, confere que todo organismo, ou seja, a pessoa em sua totalidade, é fundamentalmente movida por uma tendência própria, que a guia para desenvolver todas as suas capacidades e ir ao encontro de propiciar o seu crescimento e desenvolvimento. Essa tendência é inevitável na prática de todas as funções, tanto físicas quanto experienciais. Ela visa constantemente desenvolver as potencialidades do indivíduo para assegurar sua conservação e seu enriquecimento, levando em conta as possibilidades e os limites do meio. A tendência atualizante tem em vista, assim, aquilo que favorece o desenvolvimento integral do indivíduo, pelo crescimento de tudo o que tem e de tudo o que é, sobre o que é importante para ele, os seus saberes, seu poder, suas alegrias, talentos, seu prazer e tudo aquilo que aumenta a satisfação que ele obtém disso. Vale frisar, que o que essa tendência procura atingir é aquilo que a pessoa percebe como valorizador ou enriquecedor, não necessariamente o que pode favorecer o progresso da pessoa (ROGERS; KINGET, 1977). 
Tendo em vista tal tendência inerente ao desenvolvimento do ser, o terapeuta centrado na pessoa acaba se situando no lado extremo, tanto no sentido teórico quanto prático, ele compreende que as forças construtivas da pessoa podem ser confiáveis, e quanto mais de forma profunda se sustenta nelas, mais elas são estimuladas. Os fatos e hipóteses considerados com isso, é que o cliente sabe quais são as suas áreas de preocupação que está apto a explorar, é o cliente quem sabe qual o período e frequência mais desejável diante de suas sessões, o cliente pode dirigir o percurso da terapia de forma mais eficiente que o terapeuta em seus problemas mais íntimos. Compreende-se também, que ele poderá se proteger e parar de explorar áreas dolorosas de sua vida em algum momento, mas em dadas situações, consegue e revela todos os elementos que reprime e que são necessários para se ajustar. Desse modo, o cliente pode conseguir insights ${ }^{3}$ mais favoráveis e verdadeiros por si próprio do que se o terapeuta lhe tivesse dado, e ele é capaz de converter esses insights para um comportamento construtivo; do qual acaba avaliando as suas necessidades, desejos, bem como as exigências advindas do social. O cliente tem noção de quando sua terapia pode se completar e quando se sente pronto para encarrar a vida de forma independente. Mas em suma, só uma coisa é pertinente para frutificar todas essas ações e forças apresentadas: a atmosfera psicológica entre o cliente e o terapeuta (WOOD, 2010).

Nesse sentido, pode-se averiguar que a ACP entende que a pessoa tem a capacidade e o poder de distinguir, sem ser guiada, os passos que pode conduzir para um relacionamento mais maduro e confortável com a realidade (WOOD, 20I0). Destaca-se então nessa forma de atuar, que o terapeuta deve se esforçar o quanto lhe for possível em se dirigir como pessoa e não como especialista em seu fazer, tendo que ter uma atuação que consista em pôr em prática algumas atitudes e concepções fundamentais relativas ao ser humano em seus contatos terapêuticos (ROGERS; KINGET, 1977).

\footnotetext{
3 O Insight é o momento em que a pessoa verbaliza uma compreensão em relação aos seus sentimentos (ROGERS, 198I). Para Rogers (2005), o termo implica percepção de um novo sentido na experiência do indivíduo. Na qual ele observa novas relações de causa e efeito, alcança um novo entendimento do sentido que têm os seus sintomas na conduta, compreende então, o modelo do próprio comportamento. Trata-se de uma aprendizagem própria desenvolvida pela pessoa que, inevitavelmente, constrói uma modificação na compreensão de si.
} 
Por uma dessas atitudes, ressalta-se a congruência ou autenticidade, sendo a transparência do terapeuta diante da relação com o cliente, passando a ser ele mesmo na relação com o outro, ou seja, significa o terapeuta viver abertamente os sentimentos e atitudes envolvidos no momento da relação, é ser autêntico e genuíno com o outro (ROGERS, 1983). Ao ser verdadeiro na comunicação de seus sentimentos, Rogers acreditava que estava trazendo benefícios ao cliente, uma vez que a psicoterapia é uma oportunidade para que a pessoa possa estabelecer com o terapeuta um modo diferente e autêntico de se comunicar (RUDIO, 1999).

Outra atitude importante, trata-se da consideração positiva incondicional, sendo esse elemento enfatizado como a aceitação do terapeuta diante das experiências do cliente, abstendo-se de julgamentos, críticas, possibilitando um ambiente propício para que a pessoa se expresse conforme desejar, portanto, Rogers (1983) salienta nesse sentido que o terapeuta permita que o cliente expresse na relação o sentimento que estiver ocorrendo no momento, seja ele qual for, ressentimento, confusão, medo, raiva, amor, coragem ou orgulho.

A compreensão empática também se apresenta como uma atitude fundamental, sendo a capacidade do terapeuta em se colocar no lugar do outro, de deslocar-se de seu mundo para o mundo do cliente a fim de compreendê-lo em sua totalidade, com isso, por meio da compreensão empática, quando as pessoas são ouvidas de um modo empático, elas se aproximam de suas experiências, tornando-se mais congruentes, verdadeiras e mais genuínas (ROGERS, 1983).

Por intermédio de tais atitudes, Rogers (198I) sustenta que, quando o terapeuta é congruente ou transparente, de modo que suas palavras estejam de acordo com os seus sentimentos, ou seja, quando não se divergem, se ele tem consideração incondicional pelo cliente, bem como se o terapeuta compreende os sentimentos íntimos do cliente tal como surgem para o próprio, existe então, uma forte probabilidade de que essa relação de ajuda seja eficiente.

Esse jeito de ser do terapeuta oriundo de suas atitudes, traduz-se simplesmente que, quando essas três condições estiverem presentes na relação e o cliente as compreende pelo menos parcialmente, o movimento terapêutico continua, o cliente nota que aprende e se desenvolve, dolorosa e definitivamente, e ambos consideram que o resultado é positivo. Para 
a $\mathrm{ACP}$ as atitudes são as que merecem ser dadas atenção muito mais do que o conhecimento e as aptidões técnicas do terapeuta, são elas as principais responsáveis pela modificação terapêutica (ROGERS, 198I). Nessa forma de atuação, o papel do terapeuta é o de facilitador, acompanhando o cliente a se descobrir, para que possa identificar suas próprias potencialidades e usá-las a seu favor. O terapeuta propicia um ambiente no qual o cliente se sinta à vontade, respeitado e acolhido, favorecendo essa autodescoberta. O cliente com essa percepção, tendo como fruto a descoberta de si mesmo, torna-se capaz de se ver como protagonista da sua própria história e escolher seus próprios caminhos (MOREIRA, 20I0).

Baseado em sua experiência clínica, Rogers destacava em sua teoria da personalidade, que as pessoas usam sua experiência para se definir. Assim sendo, existe um campo de experiência único para cada pessoa, que contém tudo o que se passa no organismo, como: eventos, percepções, sensações e impactos dos quais as pessoas muitas vezes não tomam consciência (FADMAN; FRAGER, 1986).

Rogers (2003) salienta que a psicoterapia se refere primeiramente à organização e ao funcionamento do self 4 , pois existem muitos elementos da experiência que o self não é capaz de lidar. A psicoterapia centrada na pessoa possibilita um espaço adequado para o cliente entrar em contato com suas próprias experiências na relação terapeuta-cliente. Nesse sentido, ao longo da experiência terapêutica é possível a pessoa conseguir enxergar suas próprias atitudes, confusões, ambivalência, sentimentos e percepções adequadamente expressas por outro. O cliente, nesse processo, começa a observar a si mesmo indo em direção da aceitação e elaboração de todos esses elementos (ROGERS, 2003).

Assim, o cliente nessa perspectiva tem a possibilidade de analisar as suas experiências sob vários pontos de vista e da maneira que a sente, estando seguro para isso devido à atmosfera da relação terapêutica. As experiências vão tornando-se fluidas nesse processo e isso só é possível porque ele é recebido pelo terapeuta com um sentimento de empatia, aceitação e autenticidade, que colabora para uma mobilização do sujeito, que se afasta de um funcionamento fixo e desajustado. Esse processo só se desenvolve dessa forma quando o

${ }_{4}^{4}$ Trata-se de um conjunto organizado e modificável de percepções que se referem ao próprio indivíduo. Como exemplo, pode-se citar as características, particularidades, qualidades e defeitos, capacidades e limites, valores e relações que a pessoa adota como descritivas de si mesma e que percebe constituindo a sua identidade. O self também é chamado de autoconceito e de noção de eu (ROGERS; KINGET, 1977; ROGERS 1992). 
cliente sente que o terapeuta compreende as experiências relatadas e, além de compreendêlas, aponta que o sujeito é capaz de enfrentar suas experiências mesmo que elas sejam dolorosas (ROGERS, 2004).

Por conseguinte, tornar as experiências plenamente conscientes é objetivo da terapia, em que, gradativamente o indivíduo vai conseguindo aceitar a experiência dos seus sentimentos que foram negados, distorcidos, aceitando-os como parte de si. Ele passa a perceber suas experiências como um recurso de crescimento, ocorrendo uma abertura tanto ao que ocorre no interior quanto no exterior. Diante da Psicoterapia Centrada na Pessoa, desenvolve-se a capacidade de trazer à consciência as experiências que em sua vida cotidiana são negadas, sendo essas experiências incorporadas ao eu. Na terapia as mudanças mais significativas ocorrem com as experiências subjetivas e delicadas (ROGERS, 2004). Ressalta-se que a vulnerabilidade básica de uma pessoa é correspondente à incongruência entre as percepções que ela tem de si, ou seja, de suas próprias capacidades, diante das suas relações com as pessoas, e a realidade que capta do social. No momento em que a pessoa consegue abarcar a totalidade da sua experiência vivida, diferenciando-a e simbolizando-a

de forma adequada em si, vai organizando uma nova estrutura de self, e essa vai se tornando mais firme e claramente definida, servindo para traçar um caminho em direção a uma conduta mais segura e saudável na vida (ROGERS, 1975).

\section{PROCEDIMENTOS METODOLÓGICOS}

Gil (2010) ressalta que é necessário que haja a classificação da pesquisa, pois ela pode tomar rumos diferentes, levando em consideração os objetos e objetivos determinados pelos diversos tipos existentes. A natureza desta pesquisa pode ser considerada básica, pois não possuiu nenhum tipo de envolvimento comercial ou de mercado, estando relacionada com o aprofundamento científico sobre o tema pesquisado (GOBBO, 2017). Quanto à abordagem do trabalho se apresentou como qualitativa, a qual teve como propósito analisar e estudar um determinado contexto. $\mathrm{O}$ tipo de pesquisa se denominou pesquisa exploratória, que visa um acesso mais próximo do problema investigado, oferecendo informações sobre determinada temática. Por sua vez, adotou-se o método de pesquisa bibliográfica, a qual se 
baseia no levantamento de referencial já editado em relação à temática de estudo, desde teses, livros, artigos e revistas (GIL, 2010).

Nesse sentido, a coleta de dados ocorreu por meio de consulta de artigos, anais, revistas e teses nas bases de dados: SciELO Brasil (Scientific Electronic Library Online), PEPSIC (Periódicos Eletrônicos em Psicologia), EBSCOhost, (Information Services Tecnologia e Informação), CAPES periódicos (Coordenação de Aperfeiçoamento de Pessoal de Nível Superior), OASIS BR (Portal brasileiro de publicações científicas em acesso aberto). A busca realizou-se por meio dos descritores: depressão na adolescência, transtorno depressivo e adolescência, "depressão e adolescência” e depressão em adolescentes. Tendo como termos primordiais de inclusão para essa escolha, a publicação em língua portuguesa (Brasil e Portugal), textos completos, delimitando os anos de 2010 até 2020. Todo levantamento teve delimitado como parâmetro de pesquisa, documentos que incluíam algum vínculo e coerência com a temática abordada, sendo feita a leitura dos títulos e resumos, aplicado como termos de exclusão dados publicados antes de 2010, e relacionados a outros saberes. Posteriormente, fora realizada uma leitura integral, selecionando os artigos que retratavam conteúdos pertinentes ao tema.

Quanto ao método de reprodução da análise, tratou-se de uma revisão narrativa, utilizando como maneira de interpretar os dados colhidos, a Análise Temática (AT). De acordo com Souza (2019), a AT contribui pela sua praticidade e ampla aplicabilidade, já que pode ser utilizada em quase qualquer tipo de análise qualitativa. Ela se trata de um método de análise qualitativa de dados para identificar, analisar, interpretar e relatar padrões (temas), valendo-se de dados qualitativos. A AT proporciona uma maneira de organizar e descrever o banco de dados, essa espécie de análise colabora para a geração de uma análise interpretativa sobre eles. Assim sendo, em respaldo aos objetivos específicos deste trabalho, cada um consistiu em um tema para análise, do qual envolveram os conteúdos selecionados encontrados nas bases de dados mencionadas. Em remate, a interpretação se apresentou à luz do referencial teórico da Abordagem Centrada na Pessoa de Carl Rogers. A Figura I apresenta o Fluxograma metodológico da pesquisa. 
Figura I - Fluxograma metodológico da pesquisa

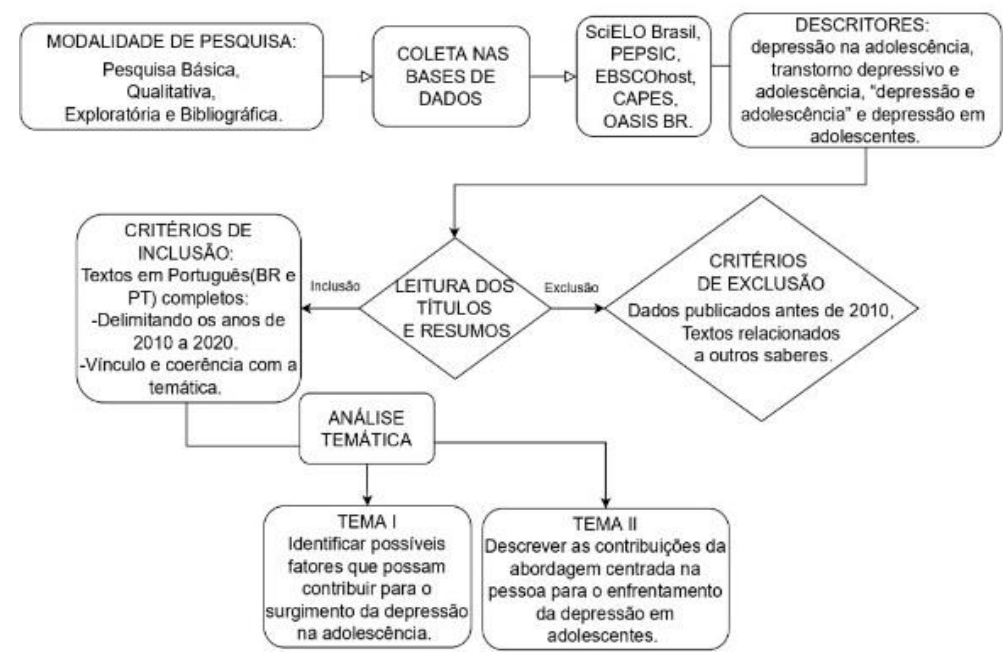

Fonte: Os autores (2021).

\section{ANÁLISE DOS RESULTADOS}

Com base na primeira unidade de análise, na qual se buscou identificar possíveis fatores que possam contribuir para o surgimento da depressão na adolescência, conteúdos apresentados por Lins (2019), Argimon (2013), Brito (2011), Meine, Cheiram e Jaeger (2019) corroboram a adolescência, como uma fase do desenvolvimento humano, caracterizada por um período de múltiplas e acentuadas transições. A adolescência é então marcada por diversas transformações, as mudanças físicas e neuroquímicas que se apresentam, as psíquicas, emocionais e comportamentais vivenciadas, bem como as realidades sociais e culturais que perpassam a vida do adolescente.

Tendo em vista a enrustida complexidade que o adolescente presencia perante a essa travessia de sua construção e desenvolvimento, culmina por ressoar a pergunta do primeiro tema de análise, que concomitantemente vem ao encontro das palavras de Baptista e Assumpção (1999), que é, o que leva uma pessoa a se deprimir? Neste caso, o que leva um adolescente a se deprimir? Esta fase da vida apresenta ser suscetível ao surgimento da depressão? Que fatores possivelmente contribuiriam para o surgimento da depressão na adolescência? 
Deparando-se com esta realidade estampada, oriunda das múltiplas transformações que abarcam essa etapa da vida, a adolescência demonstra ser um período vulnerável à instalação da sintomatologia depressiva. $\mathrm{Na}$ base característica dessas mudanças, está a alteração do corpo de criança para o de um adolescente sexuado. Ao entrar na puberdade, as alterações hormonais e morfológicas se apresentam, bem como as exigências de novas capacidades de sentir, pensar e agir. $O$ adolescente vai enfrentar a necessidade de se atualizar em relação ao seu próprio corpo, no que diz respeito à sua identidade psíquica, e ao meio social no qual está inserido (BRITO, 20II).

Susman e Rogol (2004) evidenciam em suas pesquisas, acentuada emotividade e instabilidade de humor no início da adolescência, dadas essas alterações hormonais. Com efeito, emoções perturbadoras, como angústia, hostilidade, incluindo possíveis sintomas de depressão podem estar aumentando, à medida que a puberdade prossegue. Além das alterações hormonais e morfológicas que se estabelecem, não há muito tempo, grande parte dos cientistas obtinha a crença de que o cérebro do adolescente estaria totalmente maduro na puberdade. Porém, recentemente, estudos de imageamento mostram que o cérebro do adolescente pode ser compreendido como uma construção em andamento. Existem nele, mudanças notáveis e surpreendentes nas estruturas cerebrais que envolvem as emoções, o autocontrole, nos julgamentos e em como se organiza os comportamentos, tudo isso, ocorrendo entre a puberdade e o começo da vida adulta (PAPALIA et al., 2013, p. 392). Assim, o adolescente pode estar propenso aos sintomas depressivos, em decorrência do que se passa em seu desenvolvimento vivenciado nessa fase, pois ele se encontra ainda em construção, atravessado pelas inúmeras transformações.

Como uma fase recheada de acontecimentos, a adolescência incorpora ainda características relacionadas à exploração, descobertas de múltiplas oportunidades e até mesmo descréditos. Sobre este último, frequentemente surge a resposta social de que o adolescente não tem a garantia, condição e espaço de ser autônomo em suas escolhas e atitudes (BARBOSA et al., 2016). Diversas vezes ocorrem a criação de estereótipos, negando ao adolescente o direto de falar e legitimar o que tem a dizer, entendendo que ele é imaturo para compreender coisas que muitas vezes já estão ao alcance de seu entendimento. Dessa forma, sem perceber, os adolescentes podem se tornar figuras traduzidas em estigmas, que 
acabam por formar ou deformar sua identidade. Portanto, faz-se necessário atentar-se na enorme influência que os adultos propiciam na construção da autoimagem e na identidade do adolescente. Por vezes, os que se designam como adultos sensatos por fim são os que julgam, criticam, perfazendo que os adolescentes são pessoas sem capacidade e autonomia para desenvolver suas próprias orientações, impedindo então, o desenvolvimento e apresentação das construções subjetivas que são singulares destes (CARVALHO; SALLES; GUIMARÃES, 2003).

O adolescente vive e possui seus próprios conflitos. Deseja conquistar sua autonomia em relação ao adulto, mas de alguma forma ainda depende dele. Busca ser aceito pelos amigos e pelos adultos, com os amigos, constrói-se na sua moral individual referenciada pela do grupo. E ainda, muito mais do que se tornar independente das imposições dos adultos, o adolescente quer e tem necessidade de definir e saber a que veio ao mundo, a procurar entender o seu propósito de vida, quem mesmo ele é, qual o seu potencial e papel, dentro da sociedade (LACERDA; LACERDA, 1998). Nisto, não é apenas a aparência do adolescente que está diferente de quando era criança, ele também age pensando e falando de maneiras diferentes. A forma como vem processando as informações continua a aumentar, e embora ainda alguns pensamentos possam permanecer imaturos em certos aspectos, a maioria raciocina abstratamente, e é capaz de emitir julgamentos morais aprimorados, além de ter capacidade de planejar o seu futuro de maneira realista (PAPALIA et al., 2013, p. 404). Ademais, Gutman; Eccles (2007) salientam que os adolescentes que dispõem de mais oportunidades para tomar decisões, relatam autoestima mais elevada do que aqueles que têm menos chances de discernir as suas próprias escolhas.

Identificou-se algumas dimensões de importante influência para o surgimento de manifestações depressivas nesse período da vida. No que repercute ao histórico familiar do adolescente, estudos sugerem que componentes genéticos são capazes de trazer a sua carga de contribuição. Salienta-se também, que a presença de depressão familiar aumenta o risco de depressão na infância ou adolescência em pelo menos três vezes (BIAZUS; RAMIRES, 2012).

Sobre a esfera familiar, ela pode se apresentar como um fator de influência marcante no percurso do adolescer. A família do adolescente se caracteriza como uma entidade 
essencial no desenvolvimento e amadurecimento biopsicossocial. As condições físicas e mentais promovidas pela interação com pessoas significativas no núcleo familiar, favorecem a construção de valores, crenças e padrões de comportamento que servem para uma função de ajustamento na vida (PRATTA; SANTOS, 2007). Lins (2019) destaca ainda que vivenciar superproteção materna, autoritarismo, pais com transtornos, níveis elevados de conflito entre pais e filhos, abuso físicos, psicológicos e sexuais, bem como o baixo funcionamento na dinâmica e interação familiar, pode ter uma influência negativa na saúde mental dos adolescentes. Assim sendo, considera-se uma íntima associação entre a relação familiar e a presença de sintomas depressivos e ansiosos na adolescência. Da mesma maneira, Gutman; Eccles (2007), já sublinham que as interações familiares desfavoráveis e arraigadas de negatividade se relacionam com a depressão no adolescente, em contrapartida, aquelas providas de uma identificação positiva relaciona-se a menores índices depressivos.

Uma das hipóteses mais prováveis relativas ao suporte familiar e depressão, é que, relacionamentos que carecem de afeto provido dos pais, baixa estimulação, falta de comunicação na infância e adolescência, contribuem de forma significativa para o surgimento de personalidades vulneráveis, das quais trazem um aumento na probabilidade de depressão e para padrões insatisfatórios de relacionamento (BIRTCHNELL, 1988). Krause, Liang e Yatomi (1989) enfatizam que as desordens psicológicas e, em especial, os sintomas depressivos, podem ser influenciados pela insatisfação do indivíduo diante do suporte que lhe é fornecido pelo seu grupo social. Silva et al. (2019) citam então, que além de o relacionamento familiar provido de práticas parentais incoerentes contribuírem para a depressão, condições de baixa renda, questões emocionais relacionadas à adolescência, à inserção e evasão nos diversos grupos sociais, à vulnerabilidade social, incluindo aqui o uso de álcool e drogas, maior interação com mídias digitais, bem como o sedentarismo, são também fatores marcantes que podem contribuir rumo ao desenvolvimento do quadro depressivo.

Meine, Cheiram e Jaeger (2019) atribuem plenamente a mesma relevância a essas questões mencionadas, quando assinalam que os fatores sociais, e os que se ligam a eles, são pontos que interferem de maneira significativa no desencadeamento e na evolução de quadros depressivos. Assim sendo, diante dos meios de cuidado e tratamento destinados a 
adolescentes que encaram tais situações, faz-se relevante considerar o contexto sociocultural no qual está inserido e a história de vida destes, levando-se em conta as suas vivências subjetivas. Santrock (2003) faz menção nessa perspectiva, quando destaca que as diferenças que se estabelecem nas classes sociais, questões econômicas, culturais, relativas à idade, sexo biológico, questões de gênero, e ao estilo de vida, influenciam o caminho do desenvolvimento de todo adolescente.

Sem esgotá-los, acompanha-se a diversidade de fatores que são capazes de contribuir para o desenvolvimento da depressão na adolescência. Desde as transformações físicas e neuroquímicas que se apresentam, o histórico familiar genético, questões emocionais e comportamentais vivenciadas, as dinâmicas familiares e interações sociais, e por demais, que influem marcantemente o percurso do adolescer e podem abrir brechas para o estabelecimento de quadros depressivos. Tendo em vista o fato de a depressão se tratar de uma doença multifatorial, denota-se a relevância acerca de relacionar de que formas e meios ela pode estar se manifestando no adolescente. E em resposta, principalmente, levar em conta a importância de se estabelecer atenção e amparo perante a tal fenômeno, como citam

Jatobá e Bastos (2007), a depressão na adolescência merece atenção pela sua gravidade e pelos danos que causa à saúde do adolescente. Nesse sentido ainda, outro desafio a ser apontado é que, diferenciar as mudanças de humor consideradas normais das que podem se alterar para níveis mais graves, não é uma tarefa fácil. Na depressão, os sintomas ocorrem num fluxo de gravidade, entre o humor costumeiro que por vezes implica cuidados, ou seja, aquela tristeza que tipicamente se sente e o que acaba se tornando uma doença depressiva (SAMPAIO; FIGUEIRA; AFONSO, 2014).

Inevitavelmente, reconhecer que a adolescência pode ser um período custoso e arraigado de transformações e construções subjetivas ajuda pais, professores e outras figuras sociais a buscar compreender os comportamentos de experimentação do adolescente. Mas adultos que presumem que os tidos alvoroços por vezes vividos pelo adolescente são normais, necessários, dignos de não atenção, podem deixar de perceber sinais de que eles estão necessitando de ajuda (PAPALIA et al., 2013, p. 436). À vista desses motivos, Crivelatti, Durman e Hofstatter (2006) mencionam que para verificar os sintomas básicos de depressão na adolescência, é pertinente levar em conta o humor depressivo, falta de reatividade, 
variações de humor, irritabilidade, excesso de culpa, a incapacidade de sentir prazer em atividades normalmente agradáveis, agitação motora, distúrbios alimentares, pessimismo, ideação suicida e o retraimento social.

Ao segundo tema de análise, que busca averiguar algumas das possíveis contribuições da Abordagem Centrada na Pessoa para o enfrentamento da depressão em adolescentes, vale frisar, em concordância com a ENACP (2018), que esta abordagem, é legado do norteamericano Carl Rogers, expoente nome da Psicologia Humanista. Sua contribuição à Psicologia eclodiu em diversas áreas, inclusive repercutindo fora do contexto clínico da psicologia. Ela atravessou pesquisas acadêmicas, práticas psicoterápicas, na área da educação, em trabalho com grupos. Enfim, essa abordagem por décadas de desenvolvimento, fora se tornando uma linha de ação expressivamente consolidada, no que diz respeito às relações humanas. Sua confiança incondicional na dignidade humana, no respeito, na liberdade e na diversidade humana a autenticam. O valor incessante que deposita nos potenciais criativos da pessoa para mudar e se transformar, sua ênfase em relações horizontais de poder, a aposta nos diálogos e na democracia, por vezes caem por terra, quando condizem com a realidade versada socialmente.

Para Wood (2010), a Abordagem Centrada na Pessoa não se trata de uma teoria, psicologia ou sequer uma tradição. Ela não é uma linha, por exemplo, a linha Behaviorista. Mesmo sendo situada por alguns, como tendo um posicionamento existencial em suas ações, ou por outros a referirem como uma perspectiva fenomenológica em suas intenções, não é uma filosofia, tampouco um movimento. É uma abordagem, nada mais, nada menos. Para Rogers, o autor a situa em suas palavras, que a ACP é simplesmente um jeito de ser (ROGERS, 1983).

Uma ideia central que Rogers (1983) sempre apontou, é que as pessoas possuem dentro de si mesmos amplos recursos para se autocompreenderem, para alterarem as percepções que fazem de si próprias, suas atitudes básicas e o seu próprio comportamento. E esses recursos podem ser desenvolvidos, se lhes for proporcionado um clima de atitudes psicológicas facilitadoras. O foco direcionado por essa abordagem está na pessoa, e não em seu problema, entende que a autodescoberta desta e de suas próprias potencialidades a auxilia a se desenvolver plenamente, alcançando o conhecimento de suas possibilidades, bem como 
de suas fraquezas. Objetiva-se, assim, não resolver um problema particular, mas contribuir para que a pessoa possa se desenvolver e enfrentar seus problemas atuais e futuros de uma maneira integrada (ROGERS, 1992).

Do ponto de vista dessa abordagem, tem-se então uma pessoa, na sua integralidade, não somente um adolescente, tampouco se apegar a um diagnóstico, seja ele um quadro depressivo, ou qualquer outro eventualmente vivenciado. Nisto, para essa linha de pensamento existe uma pessoa e tudo o que há de mais profundo e próprio de si. A título, haja visto a complexidade de fatores que podem possibilitar a depressão na adolescência, aqui, busca-se focalizar a pessoa por completo, procurando evidenciar como tais questões têm surtido a ela, sua forma de percebê-las, ressignificá-las e simbolizá-las em sua consciência, de acordo com seu potencial interior, e como efeito, que a pessoa possa se ajustar a tais realidades, e seguir a vida de maneira autônoma. Referente ao diagnóstico, apoiandose nas palavras de Vieira e Freire (2012) para Rogers, sustentando-se somente a este, desconsideraria a pessoa em terapia, seria como aprisioná-la em determinado diagnóstico e desconsiderá-la em sua singularidade, em resumo, deixaria de enxergá-la como uma pessoa. Acompanhou-se anteriormente que Baptista (2018) menciona que o diagnóstico tem sido utilizado como um recurso entre os profissionais de saúde. Os manuais de diagnósticos que geralmente são utilizados, segundo o autor, fazem-se importantes, visto que se apoiam em critérios universais e padronizados sobre as doenças, facilitando as intervenções e contribuindo para a comunicação dos profissionais (SAMUEL, 2005).

Em termos médicos, o diagnóstico representa uma forma de identificar uma doença, mal-estar, advindo de uma sintomatologia específica. No momento em que se desloca essa questão para a psicoterapia, o reconhecimento de algum problema se constata por meio da experiência ou comportamento da pessoa (LAMBERS, 2003). Vale esclarecer então, o que Mota (2014) impecavelmente declara, que o diagnóstico não é refutado e desvalorizado pela $\mathrm{ACP}$, pois o psicoterapeuta deve estar ciente do estado físico e mental que a pessoa apresenta. O questionamento importante que aqui se apresenta, é se existe necessidade total de um diagnóstico para a intervenção terapêutica. Se o diagnóstico é tido como a única forma de estabelecer uma prática diretiva, delibera-se que a liberdade da pessoa estará amestrada. Para a ACP o enquadramento em alguma categoria se torna rechaçado, na postura de que o 
psicoterapeuta possa estar incondicionalmente disponível em aceitar a pessoa como ela é e de suas experiências de vida, afastando-se de enquadres teoricamente fundamentados e prontos para classificar alguém.

Inicialmente, algumas das práticas terapêuticas consideravam a pessoa como uma receptora legítima de ajuda, a qual apresentava comprometimento no seu discernimento, por estar alienada do mundo ou profundamente debilitada em sua capacidade de autonomia. Um caminho interessante que vem se estabelecendo, afasta-se da psicopatologia e abrange a pessoa, no intuito de auxiliá-la a alcançar o máximo do seu desenvolvimento psicossocial possível. Essa mudança de rumo, anda juntamente a reformulação dos conceitos de doença mental e personalidade, que observa o desajustamento da pessoa como inserido num todo indivisível, que é o organismo humano, em vez de algo separado dele. Essas questões exercem hoje influência marcante, embora nem sempre explícita, no pensamento ocidental, e que são frutos que a abordagem centrada na pessoa também plantou e semeia em sua postura (ROGERS; ROSENBERG, 1977).

Por tantas vezes, métodos classificados como avançados, esquemas teóricos tidos como perfeitos, sistemas conceituais inovadores, e mesmo instituições sociais, menosprezam, manipulam, estipulam como objeto, o que é o mais importante a ser levado em conta, o ser humano. Constantemente, as pessoas são vistas como vítimas passivas de forças, sem capacidades para se autocompreenderem, tendo como destino pressões sociais, determinismos e mesmo impulsos inconscientes que fogem do seu controle. Sendo escasso, profissionais das ciências humanas defenderem o profundo direito de ser pessoa, e de proporcionar esforços para que possa restituir o seu próprio poder (ROGERS; ROSENBERG, 1977). Desse modo, nesse estilo de abordagem o psicoterapeuta se esforça em se posicionar como pessoa e não como um especialista, possuidor do saber se impondo hierarquicamente, emprega sua atuação pondo em prática atitudes fundamentais em seus contatos terapêuticos (ROGERS; KINGET, 1977).

Em outras palavras, tornando claras essas atitudes facilitadoras fundamentais, a transformação pessoal é favorecida quando o psicoterapeuta demonstra ser aquilo que é, quando suas relações com a pessoa são verdadeiras, sem fachadas, máscaras, manifestando abertamente seus sentimentos e atitudes no momento. Essa atitude é a congruência, está 
associada ao bom resultado da terapia e na maior possibilidade de que ocorra uma modificação na personalidade da pessoa. Outra condição fundamental, trata-se de quando o terapeuta se apropria de uma atitude positiva, calorosa e de aceitação daquilo que é singular da pessoa. Significa que o terapeuta esteja pronto para aceitar o sentimento que for, de maneira não julgadora, avaliativa, acompanhando a pessoa sem reservas, condições e apreciações. Esta postura se denomina aceitação positiva incondicional. Assumir esta atitude, surte probabilidades de a terapia suceder de maneira efetiva. Terceira, e não menos importante conduta, é compreender como o outro se sente e é, o terapeuta então se afasta do seu ponto de vista, de suas crenças, de suas convicções e colocar-se no lugar do outro como se fosse ele. A empatia oferece à pessoa um espaço para crescer. Quando o terapeuta é capaz de assimilar o que a pessoa está vivendo em seu mundo interior, como ela sente e vê, essa atitude também auxilia a pessoa a mudar (ROGERS, 198I).

Quando essas atitudes estão enraizadas no jeito de ser do terapeuta, seja então, na relação com o adolescente, ou melhor, com a pessoa, e estas são reconhecidas ao menos parcialmente por ela, o movimento terapêutico progride, a pessoa percebe que se desenvolve e ambos conferem que o resultado é positivo (ROGERS, 198I). O psicoterapeuta possibilita oferecer um ambiente no qual a pessoa se sinta à vontade, acolhida, respeitada, oportunizando-a se autodescobrir, o psicoterapeuta tem então o papel de facilitador, que acompanha a pessoa e a auxilia a encontrar as suas próprias potencialidades e incorporá-las em si (MOREIRA, 20I0).

Em certas ocasiões, faz-se presente na trajetória de desenvolvimento do adolescente, a noção de que são pessoas sem capacidade, autonomia, imaturidade e até mesmo os negando o que tem a dizer (CARVALHO; SALLES; GUIMARÃES, 2003). Talvez com isso, Rogers (1983) aludia a reflexão, de que quando a pessoa assume o risco de falar algo que é muito pessoal e sente que não é recebida ou entendida, vive uma experiência vazia e solitária. Chegando a concluir que uma experiência desse tipo torna algumas pessoas perturbadas. $O$ fato de ninguém estar compreendendo, as leva a perder a esperança, perdendo-a, o mundo interno da pessoa se torna cada vez mais perturbado, sendo o único lugar onde podem viver. Quando se tenta compartilhar um sentimento pessoal, privado, íntimo, e a comunicação se 
depara com uma necessidade de avaliação, comprovação, distorção do que significa, nesses momentos se entende o que é estar sozinho.

Quando a pessoa encontra alguém que ouve e aceita os seus sentimentos, aos poucos se torna capaz de ouvir a si mesma. Começam a surgir mensagens que vêm de seu próprio interior, e à medida que vai permitindo se abrir mais para o que se passa com ela, torna-se capaz de perceber sentimentos que constantemente negou e reprimiu. Então, a pessoa pode ouvir sentimentos que percebia como ruins, vergonhosos, anormais, que não seria capaz de reconhecer como existentes nela. Aprendendo a ouvir a si mesma, ela igualmente começa a se aceitar. Como expressa, um número cada vez maior de aspectos pessoais ocultos e difíceis de serem aceitos de si e percebe que o terapeuta tem para com ela e para com seus sentimentos, atitudes congruentes, empáticas e de aceitação positiva incondicional, vai lentamente adotando uma atitude idêntica em relação a si mesma, aceitando-se como é e encontrando-se no caminho da transformação. Ao ouvir com atenção seus sentimentos interiores, com menor avaliação e maior aceitação de si, vai ao encontro de uma maior congruência. Descobre que pode abandonar a fachada da qual se escondia, deixar de lado comportamentos de defesa, e ser aberta ao que é. Enquanto essas transformações vão se consolidando, a pessoa se torna mais consciente de si, aceita-se melhor, afasta-se das defesas e se vê mais aberta, percebendo que é livre para mudar e crescer (ROGERS, I98I).

No período da adolescência, a pessoa pode transitar em instabilidades na maneira como ela se percebe, ou seja, na sua noção de eu. A imagem que a pessoa tem de si, incorpora características próprias, valores e percepções subjetivas que então refletem no seu comportamento. Essa noção de eu, vai sendo construída por meio das relações sociais estabelecidas pelo adolescente com o seu meio, de um certo modo, os relacionamentos interpessoais podem favorecer o enriquecimento da imagem de si, ou, em contrapartida, bloquear um bom funcionamento do organismo (ROGERS; KINGET, 1977).

Rogers e Kinget (1977) destacam que esse bloqueio denota uma perda da liberdade experiencial, que envolve uma certa desordem do sistema de comunicação interno da pessoa, fazendo com que ela se sinta ameaçada em sua relação com o meio externo, tal qual não lhe é permitido sentir o que experimenta. Existindo, assim, o fenômeno da angústia causado por essa ameaça. Do mesmo modo que ocorre esse bloqueio experiencial da pessoa com o seu 
meio, ela, por sua vez, irá reprimir cada vez mais os seus sentimentos, comportando-se de forma inautêntica para agradar as pessoas significativas que vivem ao seu redor. A pessoa acaba por viver o contrário daquilo que sente.

Portanto, tornar as experiências conscientes é objetivo da terapia, de forma que pouco a pouco a pessoa vai aceitando a experiência dos seus sentimentos que foram negados, distorcidos, aceitando-os como parte de si. Ela passa a perceber suas experiências como meios de crescimento, abrindo-se ao que se passa em seu interior e exterior (ROGERS, 2004). Ao referir-se a tal assunto, Rogers (2003) evidencia no início do processo terapêutico, que a pessoa geralmente manifesta uma grande dificuldade em reconhecer o ser verdadeiro eu. No decorrer do processo, vai trazendo para o nível da consciência a sua essência. Isso ocorre na medida em que a pessoa caminha em direção à sua própria experiência, da qual apresenta sua satisfação em viver sua verdadeira essência, dito de outro modo, a pessoa apresenta maior espontaneidade e autenticidade. Em estudos sobre o self, Rogers acompanhou uma tendência para que a aceitação dele aumente no decorrer da terapia. A pessoa vai tendendo a reconhecer a si mesma como uma pessoa de valor, digna de confiança e respeito, baseando-se, sobretudo, na sua experiência mais do que nas atitudes ou desejos dos outros (ROGERS, 2003).

Rudio (1999) proclama que nesse tipo de terapia, considera-se que todo ser humano possui um processo natural e permanente de desenvolvimento, e a pessoa está sempre em busca de sua autorrealização. Quando esse fato não ocorre, é porque existem barreiras impedindo o processo. O terapeuta então torna-se um facilitador, ajudando a pessoa a contar com a força natural que ela já porta dentro de si. E o trabalho terapêutico consiste em criar um ambiente favorável, com atitudes fundamentais, para que a pessoa consiga perceber e se libertar dessas barreiras que impedem o seu desenvolvimento. Trazer para a realidade as potencialidades humanas de crescimento, criatividade, considerando a pessoa no aqui agora, pondo em evidência o lugar do eu, bem como atribuir importância tanto à experiência quanto ao comportamento, são pedras fundamentais da abordagem centrada na pessoa (EVANS, 1979).

Findado a segunda unidade de análise, elucidando algumas contribuições do processo psicoterapêutico à luz da $\mathrm{ACP}$, no tratamento da depressão em adolescentes, nota-se desde 
a primeira unidade descrita, a relevância de identificar possíveis fatores que possam contribuir para o surgimento da depressão nessa fase do desenvolvimento humano. Possibilitando então, estabelecer ações diante de tal fenômeno com intervenções e recursos efetivos, ciente dos danos que a depressão eventualmente venha causar à saúde do adolescente. Em concordância com a OPAS (202I) existem recursos eficazes para tratar a depressão moderada e em casos graves. Profissionais da área da saúde fornecem tratamentos psicológicos, como a psicoterapia, ativação comportamental, terapia cognitivo comportamental, psicoterapia interpessoal, em conjunto ou não com medicamentos antidepressivos. Para os que atuam no âmbito da saúde, acerca desse último, vale ter em consideração os possíveis efeitos desfavoráveis que se associam à utilização de medicamentos antidepressivos e na possibilidade de ofertar outro tipo de intervenção, podendo levar em conta seus conhecimentos técnicos, relativos ao tratamento e pelas preferências individuais.

Fazendo menção acerca da utilização de medicamentos pela população, Nazario e Silva (2015) enfatizam que nas primeiras décadas no século XXI, o uso de psicotrópicos é uma opção cada vez mais buscada pelas pessoas e por vezes também é reforçado pela área médica. Os medicamentos psicotrópicos possuem como principal objetivo o tratamento de pessoas em sofrimento psíquico, sendo prescritos e utilizados para as mais diversas situações. Estudos ainda apontam que entre os mais consumidos pela população se destacam os utilizados para o estresse, depressão, a ansiedade, insônia, problemas sociais, entre outros.

Constata-se que em determinadas ocasiões, o uso de fármacos psicoativos se faz necessário e são eficazes. No entanto, o comportamento abusivo perante estes e a automedicação são contestáveis (MONTEIRO, 2008). O uso exagerado desses medicamentos tornou-se um fato que preocupa as autoridades de saúde na sociedade atual, pois é reconhecido que a utilização prologada destes, além de resultar em efeitos colaterais não desejáveis, provoca dependência química e dificuldades ao cessar o tratamento. Como se nota a sociedade pós-moderna tem vivido características diferenciadas, trazendo implicações sobre as pessoas. O ritmo de vida acelerado, cobranças de produtividade, exigências de aparentar felicidade e demonstrá-la ao preço que for, rapidez ao acesso das informações, avanço da ciência, imediatismo nas relações, e demais questões ocorridas, 
resultam em levar as pessoas a buscarem soluções práticas e rápidas a seus problemas como resultado a estes fenômenos (NAZARIO; SILVA, 2015).

Por vezes, os medicamentos surgem como uma dessas fontes de procura, na busca de soluções práticas e ágeis às circunstâncias e exigências da vida. A OPAS (2021) ressalta que os antidepressivos não podem ser usados em crianças e não são a primeira opção para tratar os adolescentes, advertindo-se cuidado em sua utilização. Sobre os tratamentos psicológicos a serem considerados, estão os individuais ou em grupo, sendo ofertados por profissionais ou por futuros psicoterapeutas supervisionados. Destaca-se ainda que para a depressão manifestada de maneira leve, os tratamentos psicossociais também se apresentam de maneira efetiva.

Em última análise, aludindo às intervenções com tratamentos psicológicos, a ACP destacada neste trabalho, torna-se uma opção a ser considerada em face do cuidado no percurso do adolescer e em possíveis quadros depressivos que possam emergir. Ela assume a sua premissa central se apoiando no crescimento e desenvolvimento pessoal, este que permite tornar a pessoa ser ela mesma e capaz de dar voz a si e se ajustar as realidades e exigências da vida. Conceber a pessoa no seu mais íntimo mundo, visando integrar e atualizar o que se tem de mais profundo, os sentimentos e a experiência humana, são objetivos que ela carrega e deseja contribuir como ciência.

\section{CONSIDERAÇÕES FINAIS}

A depressão sendo um fenômeno de caráter ascendente na sociedade pós-moderna vem refletindo no aumento do número de adultos depressivos, e não tem poupado seus efeitos também no período da adolescência. Tem despertado a necessidade de constantes estudos e pesquisas acerca desta temática, em tentativas de elucidar como o fenômeno vem se constituindo histórico e culturalmente nos seus aspectos biopsicossociais, o que pode ser feito diante do seu surgimento, buscando propostas e intervenções que possam amparar a pessoa acometida pelo quadro depressivo.

Nesse sentido, este trabalho teve como objetivo elucidar como a depressão na adolescência pode ser possivelmente compreendida e manejada pela ACP. Procurou-se inicialmente identificar possíveis fatores que possam contribuir para o surgimento da 
depressão na adolescência, assim, expondo, uma perspectiva de atuação perante essa abordagem psicológica. Durante a pesquisa, na primeira unidade de análise ampliou-se a compreensão desse fenômeno, identificando a diversidade de fatores que são capazes de contribuir para o seu desenvolvimento, o que caracteriza por que essa doença é tida como uma doença multifatorial. Desde as transformações físicas e neuroquímicas que se apresentam, o histórico familiar genético, questões emocionais e comportamentais vivenciadas, estereótipos empregados sobre os adolescentes, possíveis influências dos adultos, as dinâmicas familiares e interações sociais, atravessam marcantemente o percurso do adolescer, e em resposta, podendo contribuir para o surgimento da depressão nessa fase do desenvolvimento humano.

Em relação à compreensão e manejo que a $\mathrm{ACP}$ pode fornecer diante da depressão na adolescência, descrita na segunda unidade de análise, constataram-se contribuições em sua forma de atuação. Ela procura focalizar a pessoa de maneira integral, tendo a confiança em algo fundamental e inerente a todo ser humano, a tendência atualizante. Que é o impulso e capacidade de cada pessoa ao crescimento e atualização, para compreender a si mesmo, para modificar as percepções que possui de si, suas ações e seu comportamento. Desde que se crie um ambiente favorável com atitudes fundamentais, para que a pessoa consiga se expressar, perceber-se e libertar-se de barreiras que impeçam o seu desenvolvimento. A ACP então, enaltece atitudes que enrustidas no jeito de ser do terapeuta e estabelecidas na relação, proporcionam um clima facilitador. Este vem ao encontro dos caminhos do crescimento e desenvolvimento do ser humano, visto que possibilita a percepção da pessoa de suas potencialidades, como também de suas dificuldades. Permite que a pessoa seja capaz de simbolizar em sua consciência, questões que rejeitava, deformava ou apropriava de maneira incongruente em si, contribuindo, assim, para que ela se desenvolva de acordo com o seu potencial interior e que tenha como resultado, seguir a vida de maneira fluida e autônoma.

Em palavras finais, a metodologia utilizada permitiu a condução da pesquisa, sendo possível discutir e analisar os conteúdos selecionados, gerando uma escrita interpretativa sobre eles nos temas de análise. Os referenciais teóricos utilizados proporcionaram conteúdos pertinentes para elaborar a escrita e transmitir a produção narrada. Além do que foi discutido, surgiram outras questões que não foram contempladas neste trabalho e que 
supostamente se tornam relevantes investigar em futuras pesquisas, tendo em vista as possíveis complicações que essa doença pode manifestar nessa fase do desenvolvimento humano. Estas seriam, o impacto da pandemia COVID-ıg e a depressão na adolescência, bem como a depressão na adolescência relacionada ao ambiente escolar, acadêmico, no início da carreira profissional e em questões relacionadas ao sexo e gênero.

\section{REFERÊNCIAS}

AMATUZZI, M. M. Por uma Psicologia Humana. São Paulo: Alínea, 2ooı.

AMERICAN PSYCHIATRIC ASSOCIATION. Manual diagnóstico e estatístico de transtornos mentais: DSM-5. 5. ed. Porto Alegre: Artmed, 2014.

ANDRETTA, I.; OLIVEIRA, M.S. Manual prático de terapia cognitivo-comportamental. São Paulo: Casa do Psicólogo. 201 .

ARGIMON, Irani Iracema de Lima et al. Intensidade de sintomas depressivos em adolescentes através da escala de depressão de Beck (BDI-II). Bol. - Acad. Paul. Psicol. São Paulo, v. 33, n. 85, p. 354-372, dez. 2013. Disponível em: http://pepsic.bvsalud.org/scielo.php?script=sci_arttext\&pid=SI4I571IX 2013000200010\&lng $=p t \& n r m=$ iso. Acesso em: 5 jul. 2021.

BAPTISTA, M. N. Manual técnico da Escala Baptista de Depressão em Adultos. (EBADEP-A). São Paulo: Vetor. 2012.

BAPTISTA, M.N., Assumpção Júnior, F.B. Depressão na adolescência: Uma visão multifatorial. São Paulo: EPU. 1999.

BAPTISTA, Makilim Nunes. Avaliando "depressões": dos critérios diagnósticos às escalas psicométricas. Aval. psicol., Itatiba, v. 17, n. 3, p. 301-310, 2018. Disponível em: http://pepsic.bvsalud.org/scielo.php?script=sci_arttext\&pid=Si67704712018000300004\&lng=pt\&nrm=iso. Acesso em: 4 mar. 2021.

BARBOSA, Diego Grasel et al. Sintomas depressivos em adolescentes em situação de vulnerabilidade social. Cad. saúde colet., Rio de Janeiro. v. 24, n. 2, p. 221-227, jun. 2016.

BERGER, Kathleen Stassen. O desenvolvimento da pessoa da infância à adolescência. 5. ed. Rio de Janeiro: LTC, 2003.

BIAZUS, Camilla Baldicera; RAMIRES, Vera Regina Röhnelt. Depressão na adolescência: uma problemática dos vínculos. Psicol. estud., Maringá, v. 17 n. I, p. 83-91, Mar. 2012. 


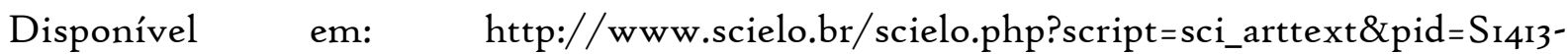
7372201200oroooro\&lng=en\&nrm=iso. Acesso em: 5 Mar. 2021.

BIRTCHNELL, J. Depression and Family Relationships. A Study of Young, Married Women on a London Housing Estate. British Journal of Psychiatry, I53: 758 - 769. 1988.

BOCK, Ana B.; FURTADO; Odair; TEXEIRA, M. de L. Psicologias: uma introdução ao estudo de psicologia. 13. ed. reform. e ampl. São Paulo: Saraiva, 1999.

BORSBOOM, D. Psychometric perspectives on diagnostic systems. Journal Of Clinical Psychology, 64(9), I089-I108. doi: 10.1002/ jclp.20503. 2008. Disponível em: https://onlinelibrary.wiley.com/doi/ı.1002/jclp.20503 Acesso em: 4 mar. 2021.

BRASIL. Lei 8.069, de 13 de Julho de 1990. Estatuto da Criança e do Adolescente. Brasília: Ministério da Justiça, I99o.

BRITO, Isabel. Ansiedade e depressão na adolescência. Revista Portuguesa de Clínica Geral, v.27, n.2, p.208-214, Lisboa, 2011. Disponível em: https://www.rpmgf.pt/ojs/index.php/rpmgf/article/view/ro842/ro578. Acesso em: 5 jul. 2021. doi: http://dx.doi.org/ro.32385/rpmgf.v27i2.10842.

CARVAlHO, Alysson Massote; SAlleS, Fátima; GUIMARÃES, Marília Marques.

Adolescência. Belo Horizonte: Instituto de Filosofia e Teologia de Goiás, 2003.

CHIZZOTTI, Antonio. Pesquisa qualitativa em ciências humanas e sociais. Petrópolis: Vozes, 2006.

CONSELHO FEDERAL DE PSICOLOGIA (BRAZIL). Quem é o psicólogo brasileiro?. Edicon, 1988.

COSLIN, Pierre G. Psicologia do Adolescente. Lisboa: Instituto Piaget. 2009.

CRIVELATTI, Marcia Manique Barreto; DURMAN, Solânia; HOFSTATTER, Lili Marlene. Sofrimento psíquico na adolescência. Texto contexto - enferm., Florianópolis, v. I5, n. spe, p. 64-70, 2006. Disponível em: http://www.scielo.br/scielo.php?script=sci_arttext\&pid=Soro4-

07072006000500007\&lng=en\&nrm=iso. Acesso em: 5 mar. 2021.

EISENSTEIN, Evelin. Adolescência: definições, conceitos e critérios. Adolescência e Saúde. Abr/Jun 2005; vol. 2, no 2, p.6-7. Disponível em: https://pesquisa.bvsalud.org/adolecbr/resource/pt/abr-45I. Acesso em: 2 mar. 202I.

ENACP - Revista Científica e Tecnológica. Fundação Sousândrade de Apoio ao Desenvolvimento da UFMA - São Luís, v.4, número especial, out. 2018. 
FADIMAN, J.; FRAGER, R. Teorias da personalidade. São Paulo: Harbra,I986.

FERREIRA, M.; NELAS, P. B. Adolescências... Adolescentes.... Millenium: Revista do ISPV, Online. 2006;(32):I41-162. Disponível em: https://www.researchgate.net/publication/277166024_Adolescencias_Adolescentes. Acesso em: 3 mar. 202I.

FIGUEIREDO, L.C.M. e SANTI, P.L.R. - Psicologia: uma (nova) introdução - São Paulo: Educ, 1997 MEIRA, Cláudia Hyala Mansilha Grupe; NUNES, Maria Lúcia Tiellet. Psicologia clínica, psicoterapia e o estudante de psicologia. Paidéia (Ribeirão Preto), v. 15, n. 32, p. 339-343, 2005.

FIOCRUZ, Fundação Oswaldo Cruz. Saúde mental e atenção psicossocial na pandemia Covid 19: Orientações gerais. Disponível https://efg.brasilia.fiocruz.br/ava/pluginfile.php/ $73427 / \mathrm{mod}$ _resource/content $/ 3 / \mathrm{cartilha}$ _recomenda\% $\mathrm{C}_{3 \%} \mathrm{~A}$ 7\% $\mathrm{C}_{3 \%}$ B5es_gerais.pdf Acesso em: I5 ago. 2021.

FONTGALLAND, R. C; MOREIRA, V. Da empatia à compreensão empática: evolução do conceito no pensamento de Carl Rogers. Dissertação (Mestrado em Psicologia) UFMG, Ribeirão Preto, 2012. Disponível em: http://www.fafich.ufmg.br/memorandum/wpcontent/uploads/2012/1o/fontgallandmorei raoi.pdf Acesso em: 27 ago. 2021.

GIL, Antonio Carlos. Como elaborar projetos de pesquisa. 5. ed. São Paulo: Atlas, 2010.

GOBBO, André. Ciência e metodologia da pesquisa e do trabalho científico. Faculdade Avantis. 2017.

GONDRA, J.M. La psicoterapia de Carl Rogers, Bilbao: Desclée de Brouwer, I98I.

GUTMAN, L. M. \& ECCLES, J. S. Stage-environment fit during adolescence: trajectories of family relations and adolescent outcomes. Developmental Psychology. 2007.

HALL, C.S; LINDSEY, L.; CAMPBELL, J.B. Teorias da personalidade. Porto Alegre: Artes Médicas Sul, 2000.

JATOBÁ, JOANA D’ARC VILA NOVA; BASTOS, OTHON. Depressão e ansiedade em adolescentes de escolas públicas e Privadas. J. Bras. Psiquiatr., v. 56, n. 3, p. 171-179, 2007. Disponível em: https://www.scielo.br/pdf/jbpsiq/v56n3/a03v56n3.pdf. Acesso em: 5 mar. 2021. 
JOHN HOPKINGS UNIVERSITY. HUB. Depression on the rise among teens, especially girls, John Hopkings study fins. Disponível em: https://hub.jhu.edu/20r6/rI/r6/adolescentdepression-study/ Acesso em: 19 mar. 2021.

KRAUSE, N.; LIANG, J. E YATOMI, N. Satisfaction with Social Support and Depressive Symptoms: A Panel Analysis. Psycology and Aging, 4 (I): 88 - 97. 1989.

LACERDA, Catarina Augusta de Oliveira Pasin de; LACERDA, Milton Paulo de. Adolescência: problema, mito ou desafio. Petrópolis, Rio de Janeiro, ed. Vozes, 1998.

LAMBERS, E. The person-centered perspective on psychopathology: the neurotic cliente. In: D. Mearns. Developing person-centered counselling. London: Sage. 2003.

LEVISKY L. D. Depressões narcísicas na adolescência e o impacto da cultura. Psychê, 2002.

LINS, Jhésyka Evelin Mendes. Percepção de apoio familiar na adolescência e sua relação com ansiedade generalizada e depressão maior. 2019. 6ifl. Dissertação (Mestrado) Universidade Católica de Pernambuco. Pró-reitoria de Pesquisa e Pós-graduação. Mestrado em Psicologia Clínica, 2019.

MEINE, I. R.; CHEIRAM, M. C.; JAEGER, F. P. Depressão e suicídio: o adolescente frente a fatores de risco socioculturais. Research, Society and Development, [S. l.], v. 8, n. 12, p. e448121882, 2019. DOI: I0.33448/rsd-v8ir2.1882. Disponível em: https://rsdjournal.org/index.php/rsd/article/view/r882. Acesso em: 5 jul. 202I.

MELO, A. K., SIEBRA, A. J., \& MOREIRA, V. Depressão em adolescentes: revisão da literatura e o lugar da pesquisa fenomenológica. Psicologia: Ciência e Profissão, 37(I), 18-34. 2017. https://doi.org/10.1590/1982-37030001712014.

MINISTÉRIO DA SAÚDE. Depressão: causas, sintomas, tratamentos, diagnóstico e prevenção. 2019. Disponível em: http://portalms.saude.gov.br/saude-de-a-z/saudemental/depressao Acesso em: 19 mar. 2021.

MINISTÉRIO DA SAÚDE. Plano de contingência nacional para infecção humana pelo novo Coronavírus 2019-nCoV: centro de operações de emergências em saúde pública (COEnCoV) Brasília. 2020.

MONTEIRO, João Pedro Nascimento. Depressão e ideação suicida em adolescentes: as várias faces da institucionalização. Dissertação (Mestrado em Psicologia Clínica) Universidade de Trás-os-Montes e Alto Douro. Vila Real, 2012. Disponível em: https://repositorio.utad.pt/bitstream/ro348/2795/I/msc_jpnmonteiro.pdf Acesso em: 5 mar. 2021. 
MONTEIRO, Verônica de Fátima Ferreira. Perfil dos Medicamentos Ansiolíticos Atendidos na Farmácia Municipal de Campos dos Goytacazes - RJ NO ANO DE 2008. Disponível em: www.fmc.br/tcc25.pdf. Acesso em: 2 set. 2021.

MOREIRA, Virginia. Revisitando as fases da abordagem centrada na pessoa. Estudos de Psicologia (Campinas), v. 27, n. 4, p. 537-544, 2010.

MOTA, Catarina Pinheiro. Não diretividade: avaliação, diagnóstico e a terapia centrada no cliente. Rev. abordagem gestalt., Goiânia, v. 20, n. 2, p. 198-205, dez. 2014. Disponível em: http://pepsic.bvsalud.org/scielo.php?script=sci_arttext\&pid=SI8o9$68672014000200007 \& \operatorname{lng}=$ pt\&nrm=iso. Acesso em: Iㅇo out. 2021.

NASARIO, Marcela.; da SILVA, Milena, Mery. O Consumo Excessivo de Medicamentos Psicotrópicos na Atualidade. In: Centro Universitário para o Desenvolvimento do Alto Vale do Itajaí - UNIDAVI. Disponível em: http://www.uniedu.sed.sc.gov.br/wpcontent/uploads/2016/o2/Marcela-Nasario.pdf. Acesso em: Io set. 202I.

ORGANIZAÇÃO MUNDIAL DE SAÚDE. Classificação Estatística Internacional de Doenças e Problemas Relacionados à Saúde. Disponível em: http://www.datasus.gov.br/cidı/V2008/WebHelp/cidıo.ht m Acesso em: 3 mar. 202I.

ORGANIZAÇÃO PAN AMERICANA DE SAÚDE; ORGANIZAÇÃO MUNDIAL

DA SAÚDE. Depressão, Folha Informativa. Disponível em: https://www.paho.org/pt/topicos/depressao Acesso em: 2 mar. 202I.

PAPALIA, Diane E.; FELDMAN, Ruth Duskin. Desenvolvimento Humano. 12. ed. Porto Alegre: AMGH Editora Ltda., 2013.

PRATTA, Elisângela Maria Machado; SANTOS, Manoel Antonio dos. Família e adolescência: a influência do contexto familiar no desenvolvimento psicológico de seus membros. Psicol. estud., Maringá, v. 12, n. 2, p. 247-256, Aug. 2007. Disponível em: http://www.scielo.br/scielo.php?script=sci_arttext\&pid=SI4I3-

73722007000200005\&lng=en\&nrm=iso. Acesso: 24 abr. 2021.

ROGERS, C. R. Terapia Centrada no Cliente. São Paulo: Martins Fontes, 1975.

ROGERS, Carl R.; ROSENBERG, Rachel L. A Pessoa como Centro. São Paulo: EPU, i977.

ROGERS, C. R.; KINGET, G. M. Psicoterapia e Relações Humanas. 2. ed. Belo Horizonte: Interlivros, 1977.

ROGERS, Carl R. Um jeito de ser. São Paulo: EPU, 1983.

ROGERS, C. R. Tornar-se pessoa. 5. ed. São Paulo: Martins Fontes, 198I. 
ROGERS, C. R. Uma teoria da personalidade e do comportamento. In: ROGERS, C.R. Terapia centrada no cliente. Tradução Cecília Camargo Bartalotti. São Paulo: Martins Fontes, 1992.

ROGERS, Carl R. Terapia centrada no cliente. Edital-Editora da Universisade Autónoma de Lisboa, 2003.

ROGERS, C. R. Quando Fala o Coração. São Paulo: Vetor. 2004.

ROGERS, C. R. Psicoterapia e Consulta psicológica. Lisboa: Ed. Moraes Editores. 2005.

RUDIO, Fraz Victor. Orientação não-diretiva na educação, no aconselhamento e na psicoterapia. 13. ed. Petrópolis: Vozes, 1999.

SAMPAIO, D.; FIGUEIRA, M.L.; AFONSO, P. Manual de Psiquiatria Clínica. Lisboa: Lidel. 2014.

SANTROCK, John W. Adolescência. 8. ed. Rio de Janeiro: LTC, 2003.

SCHULTZ, Duane P.; SCHULTZ, Sydney Ellen. História da psicologia moderna. 2005.

SILVA, Daniel Oliveira; SILVA, Gabriela Garcia Vieira; ANDRADE, Juliane Marques; SALOMÃO, Luiz Fernando Nogueira; TRINDADE, Venâncio Tavares Trindade; BERNARDES, Cristiane Teixeira Vilhena. RESU - Revista Educação em Saúde. Fatores que influenciam a depressão na adolescência, Anápolis, v. 7, ed. I, 2019.

SOUZA, Luciana Karine de. Pesquisa com análise qualitativa de dados: conhecendo a Análise Temática. Arq. bras. psicol., Rio de Janeiro, v. 71, n. 2, p. 51-67, 2019. Disponível em: http://pepsic.bvsalud.org/scielo.php?script=sci_arttext\&pid=Sı8o9-

52672019000200005\&lng=pt\&nrm=iso. Acesso em: 9 abr. 2021.

VIEIRA, E. M. \& FREIRE, J. C. Psicopatologia e Terapia Centrada no Cliente: por uma clínica das paixões. Memorandum, 23,57-69. 2012.

WIDIGER, T. A., \& SAMUEL, D. B. Diagnostic categories or dimensions? A question for the DSM-V. Journal of Abnormal Psychology, II4(4), 494-504. doi: 0.1037/oo2I843X.114.4.494. 2005.

WOOD, J. K. Abordagem Centrada na Pessoa. 5. ed. Vitória: Fundação Ceciliano Abel de Almeida. 2010.

WORLD HEAlTh ORGANiZATION. Depression and Other Common Mental Disorders: Global Health Estimates. Geneva: 2017. E-book. Disponível em: https://www.who.int/mental_health/management/depression/prevalence_global_health_ estimates/en/ Acesso em: 3 mar. 202I. 
WORLD HEALTH ORGANIZATION. Preventing early pregnancy and poor reproductive outcomes among adolescents in developing countries. Geneva: 20II. Disponível em: http:// www.who.int/maternal_child_adolescent/documents/preventing_early_pregnancy/en/in dex.html. Acesso em: 2 mar. 202I.

ZANELLA, Rosana. A clínica gestalt com adolescentes: caminhos clínicos e institucionais. São Paulo: Summus, 2013. 